\title{
HUGONIOT EQUATION OF STATE OF PERICLASE TO 200 GPa
}

\author{
M. S. Vassiliou and Thomas J. Ahrens
}

Seismological Laboratory 252-21

California Institute of Technology

Pasadena, CA 91125

U.S.A.

\begin{abstract}
New shock wave data on $\{100\}$ oriented single crystal periclase covering the pressure range from 160 to 200 $\mathrm{GPa}$ suggest that $\mathrm{MgO}$ is described by a single Hugoniot up to $200 \mathrm{GPa}$, with no displacive phase transitions of volume change greater than 1-1.5 per cent. For a third order finite strain fit, with $K_{0}$ constrained to its ultrasonically determined value of 162.7 GPa, the implied $\mathrm{K}_{0}$ of $4.27 \pm 0.24$ is in agreement with ultrasonically determined value of $4.17 \pm 0.14$. The new data indicate a somewhat steeper Hugoniot than that suggested by previously published shock wave results under $120 \mathrm{GPa}$. A previously published result at $258 \mathrm{GPa}$ shows more compression in the light of the present data than would be expected for $\mathrm{Mg0}$ in the B1 structure, and may signal the onset of a phase transition, although we cannot confidently make this interpretation. If $\mathrm{Mg} 0$ forms an ideal solid solution with $\mathrm{Fe}$, our data does not support the occurrence of a significant transition in magnesiowustite at lower mantle pressures.
\end{abstract}

\section{Introduction}

Magnesium oxide is a substance of considerable geophysical interest. It has played an important role in our thinking concerning the composition of the earth's lower mantle, from the early mixed oxides model of Birch (1952) to the more recent ideas propounding an equilibrium between ferromagnesian perovskite and magnesiowustite (e.g. Liu, 1979). Because of this, as well as for other scientific and industrial reasons, periclase is an exceedingly well studied material.

There is a conspicuous lack of published data, however, in the high pressure regime above $100 \mathrm{GPa}$. The shock wave results of Carter et al. (1971) and the static high pressure data of Mao and Bell (1979) cover the range up to $120 \mathrm{GPa}$; there is then a large gap until a solitary datum of Al'tshuler et al. (1965) at $258 \mathrm{GPa}$. This is a large interval over which to extrapolate with confidence, and the Al'tshuler et al. datum was moreover obtained on an initially porous sample, making it more difficult to interpret. The pressure range above $120 \mathrm{GPa}$ has been made all the more important by the discovery of a shock induced phase transition in wustite of volume change four per cent or greater (Jeanloz and Ahrens, 1980a); a similar transition in periclase at high pressure could have significant geophysical implications. We present here the results of three shock wave experiments on single crystal periclase, covering the pressure range from 160 to $200 \mathrm{GPa}$, relate these data to previous ultrasonic, shock wave, and thermodynamic measurements, and briefly discuss possible geophysical implications.

\section{Experimental}

Samples of synthetic single crystal periclase (source: Norton Co.), on the order of $3 \mathrm{~mm}$. in thickness (Table 1) were mounted on tantalum driver plates and impacted by tantalum flyer plates launched by a two-stage light gas gun. The crystals were oriented such that the direction of impact was parallel to $\{100\}$. This orientation was more or less dictated by the physical nature of our samples; we note that a B1/B2 transition, which can be regarded as a shear transformation, might be observable

Copyright 1981 by the American Geophysical Union. at a lower pressure using a $\{111\}$ orientation (Demarest et al., 1977; see Fritz et al., 1971, for evidence of this effect in $\mathrm{NaCl}$ ).

The experimental setup used here was essentially the same as that described in detail by Jeanloz and Ahrens (1977, 1980a). Briefly, shock velocity was measured by use of arrival and buffer mirrors, whose change in reflectivity was monitored with an image-converter streak camera. Streak records were analysed by visually measuring photographic prints, digitizing the arrivals and fitting them by least squares, and, where appropriate, by performing microphotometer scans on the negatives. The most serious errors are in the measurement of shock velocity. Two important sources of error here are fuzziness of arrivals caused by crosstalk in the image converter tube, and curvature of arrivals arising from projectile distortion at high velocities. The latter is presumably caused by the inertia of the tantalum flyer plate relative to its lexan casing (Bernier, 1977; Bernier and Valadon, 1979). Projectile bowing is accounted for by appropriately fitting the curvature of the first arrival (Jeanloz and Ahrens, 1980a; Vassiliou and Ahrens, manuscript in preparation), rather than treating the streak record as a set of parallel lines. Particle velocity is obtained by impedance matching (McQueen et al., 1970), and the data are transformed to pressure-density space via the Rankine-Hugoniot relations. The error analysis is similar to that described by Jackson and Ahrens (1979). Formal errors in density (the largest error) are generally between 1 and 1.5 per cent.

\section{Results and Discussion}

The results of the three experiments are tabulated in Table 2 , and plotted in Figs. 1 and 2 along with shock wave data from other investigators. Examining Fig. 1, we see that the present results are quite consistent with those of Carter et al. (1971), obtained at Los Alamos Scientific Laboratory (LASL). At least squares fit of the form

$$
\mathrm{U}_{\mathrm{s}}=\mathrm{C}_{0}+\mathrm{sU}_{\mathrm{p}}
$$

to the LASL points only yields $\mathrm{C}_{0}=6.61 \pm 0.06 \mathrm{~km}$. $/ \mathrm{sec}$, $s=1.36 \pm 0.03$; to the LASL points and the present data, it yields respectively $6.61 \pm 0.05,1.36 \pm 0.02$. These lines, which are very similar, are drawn as curve 1 . We note that $C_{0}$ here is somewhat lower than the value of 6.74 which would be expected from the ultrasonically determined value of $\mathrm{K}_{0}=$ $162.7 \pm 0.2 \mathrm{GPa}$ (Jackson and Niesler, 1981). (This value is compatible with other recent measurements, for example the value of $162.1 \pm 1.7$ obtained by Bonczar and Graham, 1981; see also Spetzler, 1970). As Carter et al. (1971) noted, this discrepancy is in the wrong direction to be explainable by rigidity effects. They proposed a phase change from the B1 to the B2 structure below $20 \mathrm{GPa}$ as a possible explanation, but this is not consistent with the later static results of Mao and Bell (1979); we have no alternative explanation. One more point to note in Fig. 1 is that the present data imply less of a curvature in the Us-Up Hugoniot than might be expected from the LASL data alone (cf. curves 2 and 3 , quadratic fits to all data in the figure and to LASL data only, respectively).

Fig. 2 shows a variety of equation-of-state curves in pressuredensity space. All are third order Eulerian (Birch-Murnaghan) 
Table 1. Experimental Conditions

\begin{tabular}{|c|c|c|c|c|c|c|c|}
\hline Shot \# & $\begin{array}{l}\text { Flyer/ } \\
\text { Driver }\end{array}$ & $\begin{array}{l}\text { Buffer } \\
\text { Material }\end{array}$ & $\begin{array}{l}\text { Impact } \\
\text { Velocity, } \\
\text { km./sec. }\end{array}$ & $\begin{array}{l}\text { Bulk } \\
\text { Density, } \\
\text { g./cc. }\end{array}$ & $\begin{array}{l}\text { Archim. } \\
\text { Density, } \\
\text { g. /cc. }\end{array}$ & $\begin{array}{l}\text { Sample } \\
\text { Thekns., } \\
\text { mm. }\end{array}$ & $\begin{array}{l}\text { Buffer } \\
\text { Thekns., } \\
\text { mm. }\end{array}$ \\
\hline LGG070 & $\mathrm{Ta}$ & $\mathbf{F} \mathbf{Q}^{1}$ & $\begin{array}{l}5.585 \\
(0.05)^{2}\end{array}$ & $\begin{array}{l}3.553 \\
(0.003)\end{array}$ & $\begin{array}{l}3.580 \\
(0.003)\end{array}$ & $\begin{array}{l}2.940 \\
(0.0025)\end{array}$ & $\begin{array}{l}1.900 \\
(0.0025)\end{array}$ \\
\hline LGG102 & $\mathbf{T a}$ & $\mathbf{F Q}$ & $\begin{array}{l}6.01 \\
(0.01)\end{array}$ & $\begin{array}{l}3.569 \\
(0.003)\end{array}$ & $\begin{array}{l}3.582 \\
(0.003)\end{array}$ & $\begin{array}{l}3.114 \\
(0.0025)\end{array}$ & $\begin{array}{l}1.936 \\
(0.0025)\end{array}$ \\
\hline LGG072 & Ta & $\mathbf{F Q}$ & $\begin{array}{l}6.48 \\
(0.06)\end{array}$ & $\begin{array}{l}3.554 \\
(0.003)\end{array}$ & $\begin{array}{l}3.585 \\
(0.003)\end{array}$ & $\begin{array}{l}3.499 \\
(0.0025)\end{array}$ & $\begin{array}{l}1.863 \\
(0.0025)\end{array}$ \\
\hline
\end{tabular}

1 Fused Quartz
2 Standard error

finite strain fits, according to the formulation of Davies (1973). Although higher order expansions might be physically more realistic at high pressures, it is not generally possible in practice to determine the parameters meaningfully for such fits. As we shall see, even the third order case is difficult to fit stably when $\mathrm{K}_{\mathbf{0}}$ is not constrained by ultrasonics. We have performed two types of equation-of-state inversions: first, a two parameter inversion for $\mathrm{K}_{0}$ and $\mathrm{K}_{0}$ ' (see Appendix); and second, a simple constrained inversion for the single parameter $\mathrm{K}_{0}$;, where in this case we have constrained $K_{0}$ to be equal to Jackson and Niesler's (1981) value. Results for the parameters in several cases of interest are summarised in Table 3 . The errors given are formal standard errors of estimate. Only some of the fits are plotted in Fig. 2, partly because many of them approximately coincide. As Table 3. shows, the unconstrained inversions yield a relatively large variation in parameter values according to which points are fit. The two parameter Birch-Murnaghan inversion is somewhat less stable than the inversion for the parameters in the shock wave equation of state (eq. 1). The constrained fits are rather more uniform. All yield $K_{0}$ ' values consistent with those derived from ultrasonics: Jackson and Niesler's (1981) value for $K_{0}{ }^{\prime}$ is $4.17 \pm 0.14$. All in all, data from this study seem fairly compatible with those of Carter et al, but they do imply a certain steepening in the Hugoniot at higher pressure (compare curves 1 and 2 with curve 3 ). We might note that Bukowinski (personal communication) has done theoretical work suggesting a steeper Hugoniot than the LASL curve at high pressures.

In this light, the $258 \mathrm{GPa}$ datum of Al'tshuler et al. (1965) raises some interesting possibilities. Viewed superficially, it may seem quite consistent with the lower pressure results. We must remember, however, that this datum represents an experiment conducted on an initially porous sample. Al'tshuler et al.'s reported initial density is $3.425 \mathrm{~g}$./cc., thus a porosity of 4.4 per cent. To view this datum more meaningfully, then, we must apply some correction for the irreversible heating incurred by an initially porous sample under shock. This phenomenon is discussed in detail by Zel'dovich and Raizer (1967). We may apply Al'tshuler et al.'s equation (1):

$$
\begin{gathered}
\mathrm{P}_{\mathrm{c}}=\mathrm{P}_{\mathrm{p}}\left(\mathrm{h}-\left(\rho / \rho_{0}\right)\right) /\left(\mathrm{h}-\left(\rho / \rho_{\mathrm{c}}\right)\right) \\
\mathrm{h}=1+(2 / \Upsilon)
\end{gathered}
$$

where $P_{c}$ is crystal pressure; $P_{p}$ is porous pressure; $\rho, \rho_{c}$, and $\rho_{0}$ are respectively dynamic density, initial crystal density, and initial porous density; and $\Upsilon$ is the high pressure Gruneisen parameter. $\Upsilon$ must somehow be obtained from $\Upsilon_{0}$, the zero pressure value, assuming some form for the volume dependence. An empirical relationship of the form

$$
\Upsilon(\rho)=\Upsilon_{0}\left(\rho_{0} / \rho\right)^{\mathrm{n}}
$$

is often used (Jeanloz, 1979). Carter et al. (1971) present porous data, as well as the single crystal data shown in Figs. 1 and 2; hence, some information does exist on the volume dependence of $\Upsilon$ in Mg0. There is considerable scatter in their data, but $n=1$ in eq. 3 is consistent with their results. The vertical bar in Fig. 2 shows a range for the corrected positions of Al'tshuler et al.'s datum for zero pressure Gruneisen parameters from 1.0 to 1.5 , and $n=1$. (Available data suggests a best value of about 1.3 for $\Upsilon_{0}$ (Touloukian et al., 1977)).

Al'tshuler et al.'s corrected datum appears to indicate more compression than would be expected for $\mathrm{MgO}$ in the $\mathrm{B} 1$ structure. It is denser by about three per cent than the predicted value according to curve 1 , and about two percent compared with the predicted value from curve 2 , these curves being respectively the unconstrained and constrained fits to all data

\begin{tabular}{|c|c|c|c|c|c|c|c|c|}
\hline \multirow[b]{2}{*}{ Shot \# } & \multicolumn{4}{|c|}{ Hugoniot State } & \multicolumn{4}{|c|}{ Release State } \\
\hline & $\begin{array}{l}\text { Shock } \\
\text { Velocity } \\
\text { km./sec. }\end{array}$ & $\begin{array}{l}\text { Particle } \\
\text { Velocity } \\
\text { km./sec. }\end{array}$ & $\begin{array}{l}\text { Pressure } \\
\text { GPa }\end{array}$ & $\begin{array}{l}\text { Density } \\
\text { g./cc. }\end{array}$ & $\begin{array}{l}\text { Shock } \\
\text { Velocity } \\
\text { km./sec. }\end{array}$ & $\begin{array}{l}\text { Particle } \\
\text { Velocity } \\
\text { km./sec. }\end{array}$ & $\begin{array}{l}\text { Pressure } \\
\text { GPa }\end{array}$ & $\begin{array}{l}\text { Density } \\
\text { g./cc. }\end{array}$ \\
\hline LGG070 & $\begin{array}{l}11.70 \\
(0.17)\end{array}$ & $\begin{array}{l}3.842 \\
(0.04)\end{array}$ & $\begin{array}{l}159.7 \\
(23)\end{array}$ & $\begin{array}{l}5.29 \\
(0.05)\end{array}$ & $\begin{array}{l}9.49 \\
(0.14)\end{array}$ & $\begin{array}{l}5.28 \\
(0.09)\end{array}$ & $\begin{array}{l}110.4 \\
(3.5)\end{array}$ & $\begin{array}{l}4.33 \\
(0.17)\end{array}$ \\
\hline LGG102 & $\begin{array}{l}12.33 \\
(0.27)\end{array}$ & $\begin{array}{l}4.11 \\
(0.02)\end{array}$ & $\begin{array}{l}180.7 \\
(3.0)\end{array}$ & $\begin{array}{l}5.35 \\
(0.07)\end{array}$ & $\begin{array}{l}9.75 \\
(0.25)\end{array}$ & $\begin{array}{l}5.45 \\
(0.16)\end{array}$ & $\begin{array}{l}117.1 \\
(6.4)\end{array}$ & $\begin{array}{l}4.65 \\
(0.21)\end{array}$ \\
\hline LGG072 & $\begin{array}{l}12.64 \\
(0.15)\end{array}$ & $\begin{array}{l}4.44 \\
(0.05)\end{array}$ & $\begin{array}{l}199.3 \\
(2.7)\end{array}$ & $\begin{array}{l}5.48 \\
(0.05)\end{array}$ & $\begin{array}{l}10.39 \\
(0.13)\end{array}$ & $\begin{array}{l}5.85 \\
(0.08)\end{array}$ & $\begin{array}{l}133.8 \\
(3.4)\end{array}$ & $\begin{array}{l}4.70 \\
(0.14)\end{array}$ \\
\hline
\end{tabular}

Table 2. Results

\section{Standard Errors in Parentheses}




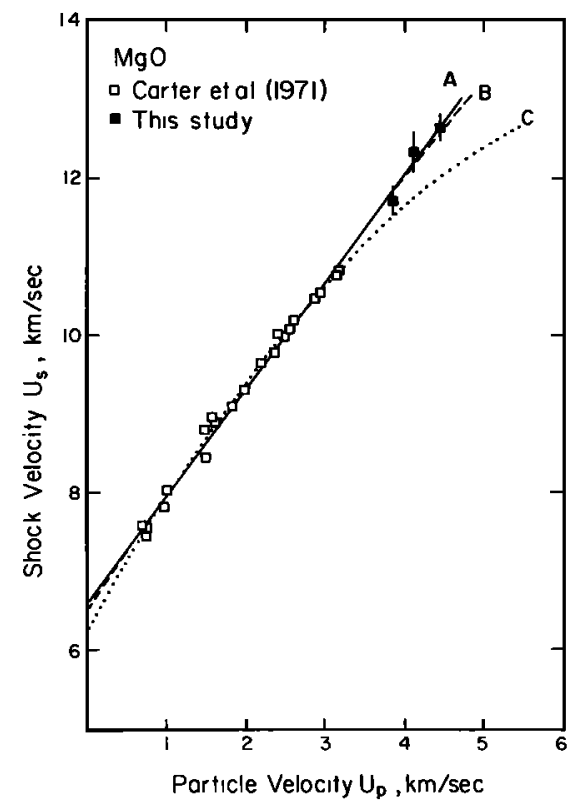

Figure 1. Shock wave data for Mgo. Curve $A=$ Linear fit to all data in figure; coincides approximately with linear fit to LASL data only (Carter et al., 1971) (eq. (1) of text ff.). Curve B = Quadratic fit to all data in figure. Curve $\mathbf{C}=$ Quadratic fit to LASL data only.

under $200 \mathrm{GPa}$. Ordinarily, we might consider this a significant deviation, and a possible indicator of a transition to a denser phase. In this case, however, great caution must be exercised before such an interpretation is made. We do not know the experimental error associated with $\mathrm{Al}^{\prime}$ tshuler et al.'s datum. We note, also, that Al'tshuler et al.'s point deviates insignificantly from curve 4 , which represents the highest density error bound

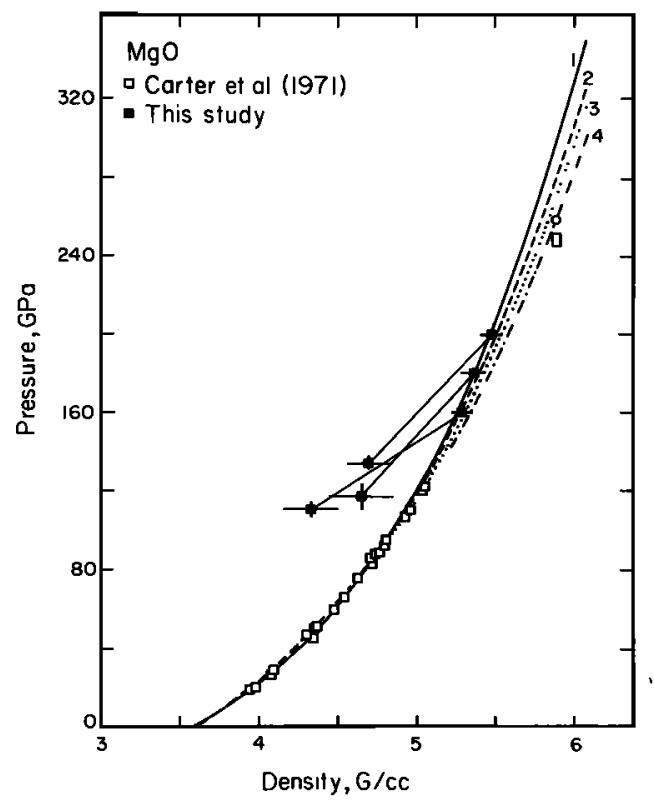

Figure 2. Pressure-Density Hugoniot equations of state (Table 3.) Open circle $=$ Al'tshuler et al. (1965) datum for 4.4 per cent porous $\mathrm{MgO}$. Open rectangle $=$ Reasonable range of pressures when Al'tshuler et al. datum is corrected for porosity. Curve $\mathbf{1}=$ Unconstrained $3^{\text {rd }}$ order fit to LASL data plus present data, Curve 2 = Constrained fit to same, Curve 3 = Constrained fit to LASL data only, Curve 4 = Highest density error bound to curve 2 .
Table 3. Equation of State

\begin{tabular}{llll}
\hline \multicolumn{4}{c}{ Parameters } \\
& \multicolumn{3}{c}{ (standard errors in parentheses) } \\
& Unconstrained & Constrained, $\mathrm{K}_{0}=162.7 \mathrm{GPa}$ \\
\hline Data Included & $\mathrm{K}_{0}, \mathrm{GPa}$ & $\mathrm{K}_{0}^{\prime}$ & $\mathrm{K}_{0}^{\prime}$ \\
LASL only & 165.7 & 4.1 & 4.19 \\
& $(3.7)$ & $(0.12)$ & $(0.16)$ \\
LASL plus & 149.2 & 4.8 & 4.27 \\
present data & $(3.7)$ & $(0.13)$ & $(0.24)$ \\
& & & 4.23 \\
$\begin{array}{l}\text { All, including } \\
\text { Al'tshuler } \\
\text { et al. }\end{array}$ & $\mathbf{1 6 9 . 8}$ & 4.03 & $(0.29)$ \\
\hline
\end{tabular}

${ }^{1}$ Corrected for porosity using $\rho \Upsilon=1.32 \rho_{0}$

to the constrained fit. One interpretation, then, is that even without error bars, Al'tshuler et al.'s datum lies marginally within the scatter of the lower pressure points.

In any case, one fairly certain and important conclusion is that up to $200 \mathrm{GPa}$ there is no phase transition in $\mathrm{Mg} 0$ involving a density change greater than 1.5 per cent or so. Though a phase change may be occurring with a volume change so small as to be undetectable by this method (systematics tell us that this is possible with certain transitions, e.g. B1 to B2 (Jamieson, 1977)), we can state with some confidence that there is no transition comparable to that observed in wustite. We note in this connection that the release data are consistent with this result; they all lie to the left of the Hugoniot in Fig. 2 and do not display the anomalous behavior sometimes associated with phase transitions (cf. the release data for $\mathrm{CaO}$ of Jeanloz and Ahrens, 1980a; Ahrens and Watt, unpublished results). By itself, the absence of a large transition in Mg0 below $200 \mathrm{GPa}$ tends to imply that contrary to the initial suspicions of Jeanloz and Ahrens (1980a), the wustite phase change is probably not directly important to the lower mantle, where pressures are less than about $130 \mathrm{GPa}$. If $\mathrm{Mg0}$ forms an ideal solid solution with $\mathrm{Fe} 0$, a significant phase change in $\left(\mathrm{Mg}_{\mathrm{x}} \mathrm{Fe}_{1-\mathrm{x}}\right) 0$, with $\mathrm{x} \geqslant 0.6$, in equilibrium with lower mantle composition $(\mathrm{Mg}, \mathrm{Fe}) \mathrm{SiO}_{3}$ (Yagi et al., 1979), is not supported by the present data. If the Fe0 transition is a simple structural one, this may simply be because the volume change decreases smoothly across the solid solution series towards Mg0. Also possible, however, is that we are dealing with a phenomenon quite localized to the iron rich end. The nature of the $\mathrm{Fe} 0$ transition is still uncertain, and recent static pressure data (Zou et al., 1980) indicate that it may be a far more complex process than originally proposed (e.g. the B1 - B2 hypothesis of Jeanloz and Ahrens, 1980a).

\section{Summary of Conclusions}

(1.) New shock wave data on Mg0 suggest that this material is described by a single Hugoniot up to $200 \mathrm{GPa}$, with no displacive phase transitions of volume change greater than 1-1.5 per cent.

(2.) For a third order finite strain fit, with $\mathrm{K}_{0}$ constrained to its ultrasonically determined value of $162.7 \mathrm{GPa}$, the implied $\mathrm{K}_{0}$ ' of $4.27 \pm 0.24$ is in agreement with the ultrasonically determined value of $4.17 \pm 0.14$.

(3.) The new data suggest a somewhat steeper Hugoniot than do existing data under $120 \mathrm{GPa}$. A $258 \mathrm{GPa}$ datum obtained by Al'tshuler et al. (1965) shows, when corrected for initial porosity, more compression by roughly two per cent than might be expected for $\mathrm{Mg} 0$ in the $\mathrm{B} 1$ structure on the basis of our data and the data of Carter et al. (1971). This may signal the onset of a phase transition, but we cannot confidently make this interpretation. 


\section{Appendix}

Finding the optimum $\mathrm{K}_{0}$ and $\mathrm{K}_{0}$ ' from Hugoniot data can, with certain assumptions, be reduced to a simple two-parameter least squares problem. In the Birch-Murnaghan case (see Davies, 1973), if we put

$$
\begin{gathered}
x=\left(\rho / \rho_{c}\right)^{1 / 3} \\
\xi_{1}=(3 / 4)\left(4-K_{0}{ }^{\prime}\right)
\end{gathered}
$$

the Hugoniot where there is no initial porosity is given by

$$
\mathbf{P}_{\mathrm{H}}=\left(\mathrm{E}_{\mathrm{S}}-\left(\mathrm{P}_{\mathrm{s}} / \rho \Upsilon\right)+\mathrm{E}_{\mathrm{TR}}\right)\left\{(1 / 2)\left(1 / \rho_{\mathrm{c1}}-1 / \rho\right)-1 / \rho \Upsilon\right\}-1
$$

with the isentropic pressure and energy $P_{s}$ and $E_{s}$ respectively given by

$$
\begin{gathered}
P_{s}=(3 / 2) K_{0}\left(x^{7}-x^{5}\right)\left[1+\left(1-x^{2}\right) \xi_{1}\right] \\
E_{s}=(9 / 2)\left(K_{0} / \rho_{c}\right)\left\{\left(1+\xi_{1}\right)\left(x^{4} / 4-x^{2} / 2+1 / 4\right)\right. \\
\left.-\xi_{1}\left(x^{6} / 6-x^{4} / 4+1 / 12\right)\right\}
\end{gathered}
$$

This is for the general case where we may have a phase transition; all quantities refer to the high pressure phase except $\rho_{c 1}$, the low pressure phase initial density. $E_{T R}$ is the transition energy.

Generally there is not enough sensitivity in a pressure-density Hugoniot data set to invert for all the unknowns, even in the third order case. We must reduce the number of unknowns by fixing $\Upsilon_{0}$ and assuming a volume dependence for $\Upsilon$. In the case of $\mathrm{Mg0}$, as discussed in the text, available data suggest $\rho \Upsilon=1.32 \rho 0$. In any case, physically reasonable variations in $\Upsilon$ do not have a significant effect on the calculated P- $\rho$ Hugoniot.

Jeanloz and Ahrens (1980b) transform (A3) to a form

$$
\mathrm{Y}\left(\mathrm{x}, \mathrm{E}_{\mathrm{TR}}, \rho_{\mathbf{c} 1}, \rho\right)=\mathrm{K}_{0}+\left(\mathrm{K}_{0} \xi_{1}\right) \mathrm{X}(\mathrm{x})
$$

where $\mathrm{Y}$ and $\mathrm{X}$ are complicated functions, and solve for $K_{0}$ and $\left(K_{0} \xi_{1}\right)$ by least squares. In this study we use a slightly different, perhaps more standard, approach. Taking $K_{0}^{0}$ and $\xi_{1}^{0}$ as initial guesses for the parameters, we compute $P_{H}{ }^{0}$ from (A2.). We then write

$$
\mathrm{P}_{\mathrm{H}}-\mathrm{P}_{\mathrm{H}}{ }^{0}=\left(\partial \mathrm{P}_{\mathrm{H}} / \partial \mathrm{K}_{0}\right) \Delta \mathrm{K}_{0}+\left(\partial \mathrm{P}_{\mathrm{H}} / \partial \xi_{1}\right) \Delta \xi_{1}
$$

where the partial derivatives are found analytically from (A1)(A4), and

$$
\begin{aligned}
\Delta \mathrm{K}_{0} & =\mathrm{K}_{0}-\mathrm{K}_{0}{ }^{0} \\
\Delta \xi_{1} & =\xi_{1}-\xi_{1}{ }^{0}
\end{aligned}
$$

We solve for $\Delta \mathrm{K}_{0}$ and $\Delta \xi_{1}$ by least squares, obtain new guesses for the parameters, and iterate until convergence is obtained.

Acknowledgements. We would like to acknowledge the invaluable laboratory expertise of $\mathbf{E}$. Gelle, $\mathbf{M}$. Long, and J. Long, without whom this study would have had much more trouble materialising. Ian Jackson, Peter Bell, and E. Graham graciously provided us with pre-publication copies of their work. Discussions with Raymond Jeanloz, Don Anderson, and Hiroo Kanamori were most helpful. This research was supported by the Earth Sciences Section, National Science Foundation, grant \#EAR 79-06766.

(Contribution \# 3594, Division of Geological and Planetary Sciences, California Institute of Technology)

\section{References}

Al'tshuler, L.V., R.F. Trunin, \& G.V. Simakov, Shock Wave Compression of Periclase and Quartz, and the Composition of the Earth's Lower Mantle, Izv. Acad. Sci. USSR, Phys. Sol. Earth, 657-660, 1965.

Bernier, H., Forme de la Face Avant -Initialement Plane- d'Un Projectile Lance par un Canon a Gaz Leger, Proc. $28^{\mathbf{T H}}$ Mtg. Aeroballistic Range Association, 1977.

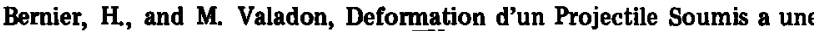
Acceleration Importante, Proc. $30^{\mathrm{TH}} \mathrm{Mtg}$. Aeroballistic Range Association, 1979.

Birch, F., Elasticity and Constitution of the Earth's Interior, J. Geophys. Res. 57, 227-286, 1952.

Bonczar, L.J., and E.K. Graham, The Pressure and Temperature Dependence of the Elastic Properties of Polycrystal Magnesiowustite, Accepted for publication, J. Geophys. Res., 1981.

Carter, W.J., S.P. Marsh, J.N. Fritz, and R.G. McQueen, The Equation of State of Selected Materials for High Pressure Reference, in Accurate Characterisation of the High Pressure Environment, ed. E.C. Lloyd, Nat. Bur. Standards Pub. 326, 147-158, 1971.

Davies, G.F., Quasi-Harmonic Finite Strain Equations of State of Solids, J. Phys. Chem. Solids 34, 1417-1429, 1973.

Demarest, H.H., R. Ota, and O.L. Anderson, Prediction of High Pressure Phase Transitions by Elastic Constant Data, in High Pressure Research: Applications in Geophysics, Eds. M.H. Manghnani and S. Akimoto, Academic Press, NY, 281-301.

Fritz, J.N., S.P. Marsh, W.J. Carter, and R.G. McQueen, The Hugoniot Equation of State of Sodium Chloride in the Sodium Chloride Structure, in Accurate Characterisation of the High Pressure Environment, ed. E.C. Lloyd, Nat. Bur. Standards Pub. 326, 201-208, 1971.

Jackson, I., and T.J. Ahrens, Shock Wave Compression of Single Crystal Forsterite, J. Geophys. Res. 84, 3039-3048, 1979.

Jackson, I. and $\mathrm{H}$. Niesler, The Elasticity of Periclase to $3 \mathrm{GPa}$ and Some Geophysical Implications, submitted to U.S.Japan Seminar on High Pressure Research: Applications in Geophysics, eds. S. Akimoto and M.H. Manghnani, 1981.

Jamieson, J.C., Phase Transitions in Rutile-Type Structures, in High Pressure Research: Applications in Geophysics, Eds. M.H. Manghnani and S. Akimoto, Academic Press, NY, 209-218, 1977.

Jeanloz, R., Properties of Iron at High Pressures and the State of the Core, J. Geophys. Res. 84, 6059-6069, 1979.

Jeanloz, R. and T.J. Ahrens, Pyroxenes and Olivines: Structural Implications of Shock Wave Data for High Pressure Phases, in High Pressure Research, Eds. M.H. Manghnani and S. Akimoto, Academic Press, NY, 1977.

Jeanloz, R., and T.J. Ahrens, Equations of State of $\mathrm{Fe} 0$ and $\mathrm{Ca0}$, Geophys. J. R. Astr. Soc. 62, 505-528, 1980a.

Jeanloz, R., and T.J. Ahrens, Anorthite: Thermal Equation of State to High Pressures, Geophys. Jour. R. Astr. Soc. 62, 529-549, 1980 b.

Liu, LG., Phase Transformations and the Constitution of the Deep Mantle, in The Earth: Its Origin, Structure, and Evolution, Ed. M.W. McElhinny, Academic Press, London, 177-202, 1979.

Mao, H.K., and P.M. Bell, Equations of State of Mg0 and $\epsilon$ Fe Under Static Pressure Conditions, J. Geoph. Res. 84, 4533-4536, 1979.

McQueen, R.G., S.P. Marsh, T.W. Taylor, S.N. Fritz, and J.W. Carter, The Equation of State of Solids from Shock Wave Studies, in High Velocity Impact Phenomena, Ed. R. Kinslow, 294419, Academic Press, NY, 1970.

Spetzler, H., Equation of State of Polycrystalline and Single Crystal Mg0 to 8 Kilobars and $800^{\circ} \mathrm{K}$, J. Geoph. Res. $752073-2087,1970$.

Touloukian, Y.S., R.K. Kirby, R.E Taylor and T.Y.R. Lee, Thermal Expansion, Nonmetallic Solids, IFI/Plenum, NY, 288ff, 1977.

Yagi, T., P.M. Bell, and H.K. Mao, Phase Relations in the System Mg0$\mathrm{Fe}-\mathrm{SiO}_{2}$ Between 150 and 200 kbar at $1000^{\circ} \mathrm{C}$, Carnegie Inst. Wash. Ybk. 78, 614-618, 1979.

Zel'dovich, Y.B., and Raizer, Y.P., Physics of Shock Waves and High Temperature Hydrodynamic Phenomena v.2, Academic Press, NY, 1967.

Zou, G., H.K. Mao, P.M. Bell, and D. Virgo, High Pressure Experiments on the Iron Oxide Wustite $\left(\mathrm{Fe}_{1-\mathrm{x}} \mathrm{O}\right)$, Carnegie Inst. Wash. Ybk. 79 374-376, 1980.

(Received Apri1 21, 1981 ; accepted May 14, 1981.) 